\title{
LA EVIDENCIA ETNOBOTÁNICA EN EL ANÁLISIS DEL TRÁNSITO DE LA ECONOMÍA RECOLECTORA A LA ECONOMÍA PRODUCTORA DE ALIMENTOS
}

\author{
Luis Guillermo Lumbreras
}

Estas notas tienen por objeto discutir la "evidencia etnobotánica" en el tránsito de la economía recolectora hacia la asentada economía productora de alimentos, es decir, el papel de la producción agraria en el paso del Salvajismo a la Barbarie ${ }^{1}$.

Esta etapa de tránsito ha sido casi siempre tratada como "Problema de los orígenes de la Cultura", habiéndose formulado soluciones autoctonistas, aloctonistas, eclécticas, etc. El hecho casi universal de la aparición de la alfarería como consecuencia del proceso, determinó, adicionalmente, que se diera un rol primario, en la discusión, a las evidencias proporcionadas por la cerámica y sus probables orígenes. La orientación dada a la discusión del problema condujo, por este método, a plantear como cuestión fundamental el origen geográfico de los inventos o descubrimientos que permitieron el desarrollo de la nueva etapa. La universalización de la cerámica como "indicador de base" permitió sugerir orígenes mesoamericanos, transpacíficos, selváticos, etc. La discusión parcial de los orígenes de algunas plantas también fue conducida al mismo terreno, de tal modo que gran parte de las conclusiones señalan "orígenes oscuros" o probablemente "alóctonos" u "autóctonos". El debate de si pudo haber difusión o descubrimiento -invención- independiente, de la agricultura, se identifica con un complicado sistema de enunciados y evidencias. Si bien es útil seguramente, tal tipo de esclarecimiento, parece que es de tan compleja solución que es fácil perder la perspectiva científica del análisis, llegando a la discusión de supuestos antes que de realidades.

Nosotros creemos que si bien interesa el lugar original y la forma cómo aparece cada nuevo elemento cultural, esto es secundario al lado del efecto que los elementos en conjunto o individualmente tienen sobre determinada formación social. Lo primario, en consecuencia, es encontrar el proceso histórico de un pueblo, analizando las características de ese proceso en función de qué cosas nuevas reemplazan a las anteriores y cómo esas cosas nuevas afectan a la estructura total de la sociedad

1 Los términos Salvajismo, Barbarie y Civilización son usados aquí a partir de la aplicación que de ellos hizo el sabio V. Gordon Childe, revaluando las originales proposiciones de Lewis Morgan y Federico Engels.

Nota: Este trabajo fue publicado parcialmente en la revista Perú Indígena № 36, 1967, Lima. 
y cómo, finalmente, eso contiene una superación de lo anterior.

En el estudio del paso de una formación social a otra diferente, al comprobar que la diferencia entre ambas está conformada por un sinnúmero de elementos, seguramente tiene interés el saber el origen de cada uno de ellos, en la misma medida en que es importante saber que alguien descubrió en Occidente, la Teoría de la Relatividad, la Cibernética, etc. pero así como es mucho más importante saber lo que esa teoría representa para el mundo contemporáneo, al que lo afecta directamente en la guerra y en la paz, así también es mucho más importante saber como intervinieron los nuevos elementos -difundidos, inventados o descubiertos- en la estructura de la sociedad; cuál fue su papel en el cambio social, independientemente de si son de aquí o acullá.

Esto significa que, es el estudio de los cambios, lo importante es encontrar los elementos que cambian; lo que es posible en Arqueología con los procedimientos metodológicos en vigencia. Las deducciones acerca del lugar de procedencia original, si bien son importantes, todavía no pueden sustentarse en todos los casos, en demostraciones absolutamente concretas. Las dificultades de los planteamientos sobre "orígenes", así como su alto contenido subjetivo, parten de la relativa incapacidad contemporánea de enfrentar las hipótesis a la realidad.

La objeción más fuerte que se podía hacer a un análisis del proceso que niega la prioridad a los "orígenes", es el de que los cambios de un estado a otro pueden haberse producido más bien que por un estímulo de desarrollo interno, como resultado de influencias del exterior ya sea por difusión o por migración. La teoría subjetivista de los "círculos culturales" parte del supuesto de que los grandes cambios culturales como consecuencia de los desplazamientos de población, más bien que de los desarrollos evolucionarios; las corrientes disfusionistas extremas, incluso conceden total vigencia a la hipótesis de que cada formación cualitativamente diferente, tienen un origen poblacional y hasta racial diferente, de tal modo de que la sociedad de alfareros agricultores, por ejemplo, se diferencian de los cazadores "paleolíticos" no solo en su conducta, sino también en su composición poblacional; para tales teóricos, el paso del Salvajismo a la Barbarie supone un desplazamiento de poblaciones que en algunos casos, incluso, determina un reemplazo de poblaciones, de tal modo que los "agricultores" destruyen a los "cazadores" o "los empujan" a rincones ecológicos despreciados por los más fuertes. Para quienes parten de estos supuestos, en consecuencia, lo importante es conocer "los orígenes" de cada elemento cultural.

Aún suponiendo que lo que sostienen los difusionistas sea absolutamente válido, la única forma de demostrarlo, no es imaginando o suponiendo lugares de origen o probables focos de difusión, sino, en principio, demostrando que la naturaleza de los cambios es de tal tipo, que no existe ligazón entre los logros de la formación social anterior y los de la nueva (para el caso de los reemplazos de población) o que los nuevos ingredientes aparecen tan fuera de una situación tradicional que cabe suponerlos importados. La ciencia, por hoy, no puede ir más allá.

Por cierto, ni los elementos asimilados por difusión se introducen dentro de la tradición, participando como factores de cambio, por mucho que su origen sea extraño, su importancia en el proceso histórico es de que actúan como factores de cambio dentro de una sociedad que los ha asimilado a su contexto y, en consecuencia, los ha incorporado a su proceso. $\mathrm{Si}$, en cambio, hay un desplazamiento de población, por el análisis contextual de la nueva estructura, se tendría que estudiar el proceso de dicha sociedad en relación con el contexto originario inmediatamente anterior, separando su análisis de la sociedad desplazada o aniquilada, que tiene una historia distinta. Las situaciones de contacto entre pueblos suponen un análisis semejante. 


\section{NATURAleza y CARÁCTER DEL PROCESO}

La naturaleza y carácter de las etapas de la historia social están dados o por un crecimiento cuantitativo de sus elementos o por un rompimiento estructural con proyecciones de cambio cualitativo. La historia registra un proceso regular de desarrollo de la Sociedad, en el que la ley universal del movimiento se manifiesta a través de los cambios de los elementos componentes de la estructura sociocultural. Se reconoce que tal tipo de conducta procesal es de carácter evolucionario, y, en este caso, la evolución es el estado permanente de la Sociedad. Quienes recurren a la difusión como fundamento del origen y contenido de los cambios olvidan que la difusión por sí misma, solamente es válida en tanto que los elementos difundidos son integrados dentro de un proceso de crecimiento dado, dentro de una evolución.

Pero la evolución por ser esencialmente la identificación del crecimiento cuantitativo de los elementos de la conducta humana, no explica en cambio cualitativo, que, al parecer sólo se produce revolucionariamente.

Mientras que el desarrollo dentro de una misma formación social, conduce solamente al "incremento" de sus propios recursos estructurales, el paso de una formación a otra, supone la negación de la estructura y su consecuente reemplazo, por esto, el estado normal, evolucionario de las formaciones sociales, sólo puede ser roto para producir el tránsito, por un proceso revolucionario.

Pero, en tanto que la evolución es la simple conducta del movimiento de la sociedad, generada por la interacción cotidiana de los hombres, la revolución es el resultado de un proceso de maduración de las condiciones de desarrollo de cada formación social, la evolución genera la revolución, en tal medida que la hace necesaria para superar las contradicciones que el proceso evolutivo produce en toda la sociedad.

Es una ley demostrada por el estudio de la historia universal que ninguna sociedad pasa de una etapa a otra sino ha logrado desarrollar el máximo de sus posibilidades de crecimiento, eso significa que es necesario la "saturación" de sus posibilidades de cambio evolutivo dentro de una formación, para que esta pueda cambiar. Pero también se demuestra, por la historia, que tal cambio, el evolutivo se realiza irregularmente dentro de cada aspecto de la estructura, de tal modo que mientras la población y la tecnología (especialmente la que está al servicio de la población) cambia aceleradamente el ritmo de la evolución en las relaciones sociales y los patrones de la conducta, tiende a ser más lento. El crecimiento irregular de las fuerzas productivas y las relaciones de producción y las ideologías consecuentes, determina que estos aspectos entren en contradicción, de tal modo que cuando el crecimiento de las fuerzas de producción han llegado a su "saturación", las relaciones, primitivamente integradas, se convierten en fuentes de sujeción de cambio, por haberse quedado muy retrasados en su crecimiento y estar en desacuerdo con tal "saturación", que, naturalmente, se producen por encima de cualquier tipo de "control" para el paso de una formación a otra, es menester el cambio estructural, y tal cambio supone la destrucción de las arcaicas relaciones productivas, de los arcaicos patrones sociales, que normalmente quedan rezagados, supone enfrentar a los diversos sectores de la estructura, para poniéndoles en un mismo nivel, equilibrar la sociedad en función de las exigencias del sector más evolucionado. En tanto no sucede este enfrentamiento, la sociedad entra en crisis, lo cual sólo culmina con la revolución.

Si estos planteamientos son ciertos, debe poder ser demostrado que el tránsito del Salvajismo a la Civilización fue un proceso de carácter revolucionario, dado que el Salvajismo es una formación social estructural cualitativamente diferente a la Barbarie.

Si se produjo, en los Andes, una revolución en el tránsito del Salvajismo a la Barbarie, debe encontrarse que el Salvajismo logró 
el máximo desarrollo de sus posibilidades, logrando su "punto de saturación" como etapa; debe encontrarse que existía ya, el germen o los gérmenes que permitieron el desarrollo de la Barbarie (pues de otro modo podría tratarse de un desplazamiento de población); debe encontrarse que las diferencias entre la Barbarie y el Salvajismo son de naturaleza estructural, de tal modo que sean totalmente distintas en la base y la superestructura; debe encontrarse que el tránsito se produjo dentro de una dimensión temporal dada, preferentemente muy corta en la que se dieron juntos "al mismo tiempo" (tiempo-época) de los internos que obligaron al "salto"; finalmente, debe demostrarse que al terminar la lucha por el cambio, la sociedad es cualitativamente diferente, negación de la precedente y de una contextura irreversible. En síntesis, si fue una revolución, debe suponer una etapa de maduración crítica de la vieja sociedad, con contradicciones provocadas por la emergencia de los gérmenes revolucionarios, generalmente dura y prolongada que debe conducir a la toma de la posición del poder revolucionario para la implementación de los cambios. Concluida esta etapa de lucha, el triunfo debe apreciarse en el cambio total de la estructura.

Frente a la posibilidad de la llegada de pueblos bárbaros de otros territorios, que desplazaron a los salvajes nativos y se establecieron en los Andes, debe aparecer que no hay ligazón germinal ninguna entre bárbaros y salvajes y que los cambios no tuvieron un crecimiento evolutivo previo, ya que los gérmenes que dieron origen a estos, deben encontrarse en los territorios de origen de los invasores; si, en cambio, los bárbaros sólo influenciaron, entonces eso sólo es parte del proceso, en donde además del descubrimiento-invención, hay el factor difusión o contacto.

Gordon Childe en el Cercano Oriente encontró que tal proceso, al que él llama "Revolución Neolítica", se produjo a consecuencia de la aparición de la tecnología agraria y sus asociados, que condujo a la sociedad de cazadores, recolectores a organizarse revolucionariamente en el nuevo régimen de la barbarie.

\section{LOS INDICADORES DEL PROCESO}

Los indicadores del cambio revolucionario son cada una de las conquistas que enriquecen una estructura. Los descubrimientos, invenciones, préstamos, asimilaciones, todos, cada cual, aumentan el caudal del desarrollo, de cada formación social; en consecuencia, cada cambio es, de por sí, un indicador social. Incluido los cambios, a veces numerosos, producidos por situaciones de contacto entre pueblos (situaciones que en algunos casos pueden acelerar el proceso y hasta provocar un cambio revolucionario).

En cambio, los indicadores del proceso revolucionario son las estructuras, y, en consecuencia, todos los componentes sociales, desde la base hasta la superestructura.

La medida del cambio revolucionario se tiene a partir de la comprobación del cambio de todos y cada uno de los elementos de la estructura, de tal modo que las estructuras así analizadas reflejan un carácter totalmente nuevo.

El objeto de estos apuntes es el de discutir sólo la evidencia etnobotánica, como indicador del cambio en la dieta alimenticia y como factor de cambio fundamental en el proceso de la producción, tratando de "descubrir" cómo fue su incorporación en el proceso, y como tal incorporación refleja la naturaleza revolucionaria del cambio. Pese a esto, creemos que conviene señalar someramente otros indicadores ${ }^{2}$.

El carácter de la sociedad salvaje estaba determinado por el recolectador, en la que la producción estaba controlada por el hombre, sólo en lo relativo a los instrumentos útiles para

2 Todo esto se discute ampliamente en "Arqueología de la Revolución", del cual este artículo es una especie de adelanto. 
la recolecta de plantas y animales (caza, pesca, etc.). El hombre dependía totalmente de la naturaleza y los productos "naturales". Esto determinó una organización social particular, con poca concentración poblacional, habitación en abrigos, cuevas o componentes estacionales, determinó una relación de total dependencia hacia las fuerzas naturales, ligándose a ellas a través de quien sabe que ideología. El equipo tecnológico de los salvajes era bastante reducido, limitado en general, a la producción de instrumentos de piedra, hueso o concha, útiles para los fines productivos ya enunciados. $\mathrm{Al}$ parecer algunos grupos predicaban ciertas formas de nomadismo estacional, de temporada de cazadores que vivían en la Sierra, bajaban a las lomas costeñas en la temporada invernal, probablemente detrás de los cérvidos y auquénidos que hacían lo propio detrás de los pastos.

La arqueología andina registra la historia de los pueblos salvajes a partir del décimo milenario antes de nuestra era, aproximadamente; se trata de pueblos probablemente emigrados de otra parte de América, adonde, por lo que se sabe, los hombres arribaron hace unos 30 milenos. El desarrollo de las fuerzas productivas propias del salvajismo se aceleró considerablemente a partir del sexto milenio antes de nuestra era, como consecuencia de un favorable cambio climático del período postglacial, que se produjo a raíz del aumento de las condiciones de humedad y temperatura de toda la región andina, posibilitando el aumento de productos útiles para la recolecta, tales como plantas y animales. Este fenómeno es conocido con el nombre de "óptimo climático". Olliver Dollfus dice que: "se caracteriza, en los Andes, por la alternancia de una estación lluviosa bastante cálida y una estación seca con vigorosos contrastes térmicos cotidianos; la nieve, en la medida en que ella existió, no tuvo un efecto morfológico, al menos debajo de los $4500 \mathrm{~m}$. Sobre la Costa esta fase se marca por el aumento del nivel de mar" (Dollfus 1965: 228).

Desde antes del "óptimo climático" de los salvajes andinos ya poseían una tecnología avanzada al servicio de la caza y la recolección, pero es a partir del año 6000 a. C. que se produce un incremento notable de su equipo instrumental, especialmente del referido de la caza: los cazadores del óptimo climático se identifican principalmente con una industria de puntas de proyectil conocida como "ayampitinense", que está asociada, regionalmente, con raspadores muy finalmente elaborados, con anzuelos de concha, con morteros para triturar granos, con chancadores, cuchillos, etc. con una producción ideológica considerable que se manifiesta en las pinturas rupestres (no siempre bien cronologizadas) y el culto a los muertos (entierros que se inician previamente), además de prácticas deformantes de la cabeza, etc.

Federic Engel (1966) ha encontrado evidencias del uso de plantas probablemente en proceso de domesticación desde este tiempo o aún antes, como veremos más adelante.

Este crecimiento acelerado de las fuerzas productivas debió producir situaciones conflictivas entre los varios sectores de la estructura que no lograron el mismo adelanto; lo evidente es que a la culminación del "óptimo climático" ya la sociedad andina había ingresado en una situación de crisis estructural que derivó en el crecimiento polarizado de sus diversos elementos, de tal modo que cuando se ingresó al período Post-glacial Tardío, de condiciones más bien desfavorables, se precipitó una situación crítica para los antiguos cazadores-relectores que tuvieron que recurrir forzosamente a una solución de lucha interna y de lucha con las relaciones previas con la naturaleza, para superar la crisis. Entre el cuarto y primer milenio anteriores a nuestra era, se desarrolló el periodo crítico de lucha por la imposibilidad de las nuevas fuerzas productivas; en esta época, a la que reconocemos con el nombre de "Arcaico", se dan todos los elementos de cambio que permitieron la formal configuración de la Barbarie, sin embargo, el gran cambio estructural se produjo sólo al final del Arcaico, en el paso al Formativo, en un tiempo bastante corto, como se verá más adelante. 
Los indicadores más importantes son el cultivo de plantas y la domesticación de animales, especialmente el primero. Como se verá la domesticación de las plantas, como técnica productiva, se origina en el Salvajismo como consecuencia de la experiencia obtenida en la recolección de plantas; su aparición no marca, como erróneamente se cree, el establecimiento de la barbarie, y si bien es cierto que es el origen de modo productivo característico de este estado, no es el único elemento indicador. Sin embargo, incluso ya dentro de la lucha revolucionaria, se considera a partir del primer estadio de la barbarie ("Arcaico"). Hay pueblos con agricultura que no han tenido una revolución "neolítica".

La caza y la pesca no son abandonados, aunque si enriquecidos con nuevos instrumentos, tales como la red, la honda, etc. El pastoreo reemplaza parcialmente a la caza, aunque este proceso pudiera ser ligeramente posterior a la agricultura.

El equipo dietético, como consecuencia del cambio de régimen alimenticio, se enriqueció notablemente, permitiendo un crecimiento demográfico explosivo.

El enriquecimiento de la industria como producto del progreso tecnológico, se proyectó en todos los órdenes de la actividad social; la industria lítica continuó, pero las técnicas de su manufactura se enriquecieron con la abrasión y el pulido; en cambio, la textilería se inició casi paralelamente al cultivo junto con la cestería; con el cultivo del algodón, el desarrollo del tejido fue notable, apareció la cerámica (importada o autóctona); la metalurgia al iniciarse el estado medio de la barbarie (Formativo), con el triunfo de la revolución, se manifestó plenamente a través del conocimiento del oro y luego del cobre y la plata.

Por otro lado, los cambios en las manufacturas y la producción agraria, posibilitaron el surgimiento del comercio internacional (o más bien intertribal).
En el orden social, el incremento poblacional posibilitó ciertos cambios paulatinos en el padrón habitacional, pasando del campamento a la aldea, abandonando la cueva para vivir en casas construidas.

La estructura social aldeana favoreció indudablemente la nucleación de la familia. La aparición de las grandes aldeas, asociadas a los centros ceremoniales es un fenómeno consecuente del triunfo revolucionario.

Junto con todo esto hay cambios indudables en la superestructura, en la religión, en el arte, que no son necesarios anotar aquí.

\section{LA EVIDENCIA ETNOBOTÁNICA}

La "evidencia etnobotánica" es de reciente registro gracias al progreso de los procedimientos científicos, muchas muestras de vegetales han sido recuperadas en los establecimientos arqueológicos; adicionalmente, las técnicas más o menos precisas de cronologización, como el radiocarbono, han permitido la ubicación temporal de las muestras y finalmente, las asociaciones que se han recuperado con las muestras permiten su ubicación dentro de un contexto cultural dado. Es así que es posible ubicar con alto grado de certidumbre de plantas en lo que parecen ser sus primeros y subsiguientes fases de existencia.

El análisis del material, por otro lado, parte de la separación de las plantas en dos grandes grupos: Cultivadas y Silvestres, y dentro de ellas, las cultivadas para usos alimenticios y cultivadas para fines no alimenticios. Nuestro énfasis se dirige a las plantas cultivadas para fines alimenticios, sirviendo ellas de índice para la medida del cambio.

Para determinar el grado de crecimiento y de "explosión" del régimen agrícola, consideramos útil tomar como referencia todas las plantas cultivadas (aparte de las que escapan a nuestro conocimiento) en tiempo de la con- 
quista española, es decir, domesticadas y/o utilizadas en tal condición en el territorio andino antes de la influencia de la sociedad europea.

La edad del salvajismo cuenta aún con pocas evidencias para su incorporación al debate, sobre todo en lo que a este tipo de evidencia se refiere, que debió ser poco importante en el contexto económico de los salvajes. De la barbarie se analizan sus dos primeros estadios: el inferior, que contiene toda la etapa de lucha y desarrollo de las condiciones revolucionaras propias de la barbarie y el medio, que se inicia con el triunfo de la Revolución -que denominaremos Agropecuaria- y continúa con su consolidación y la total configuración de la barbarie.

El estado inferior de la barbarie llamado aquí "Arcaico", tiene dos fases: la inferior, que se inicia alrededor del 4을 milenio antes de nuestra era y la superior, que comienza a mediados del tercer milenio. La Barbarie Media, llamada aquí "Formativo" tiene también dos fases, la inferior que comienza hacia 1500 a.C. y la superior cuyos inicios están fechados cerca de los comienzos del primer milenio de la era pasada (800 a 1000 a.C.). La culminación de la Barbarie Media se produce hacia 300 a.C., época en que se inicia la Barbarie Superior, cuya definición y caracterización no interesan para estas anotaciones.

Del estudio de las plantas cultivadas, en general, y de las alimenticias en particular se puede generalizar en el sentido que el 90\% de las que se conocían en los Andes a la llegada de los españoles, fueron domesticadas durante los periodos Arcaico y Formativo, habiendo concluido la domesticación en el Formativo Superior.

La domesticación se inicia hacia 3800 (o antes) y concluye hacia el 800 a.C. Del análisis de las plantas cuya datación ha sido precisada (época y/o fecha), aparece que el 14\% fueron domesticas en el Arcaico Inferior; el 33\% en el Arcaico Superior, el 27\% en el Formativo y el
$25 \%$ restante sólo tiene referencias indirectas a través del arte, en periodos muy avanzados.

De hecho, por las evidencias queda demostrado que sino el $100 \%$ al menos el $75 \%$ de las plantas con datación fueron domesticadas antes de 800 a.C. mientras que el 25\% tiene datación imprecisa y probablemente también fueron domesticadas durante el Formativo, como se verá más adelante.

Las primeras evidencias de plantas cultivadas para fines alimenticios aparecen después del año 4000 a.C., coincidiendo con la aparición del Arcaico; antes, pese a lo que señala Engel (1966: 83 y 1966a: 31) para sus hallazgos en Paracas sólo existió una economía recolectora, enriquecida por vegetales en proceso de domesticación o posteriormente domesticados. Engel, muy precipitadamente reconoce como "cultivadas" a casi todas las plantas que son encontradas en establecimientos antiguos, sin consideración que sus "restos de Tomatillo, de numerosos mates y calabazas, y de unas plantas parecidas a la yuca, que faltan identificar", pueden ser y probablemente son parte de un régimen de recolecta propio del periodo óptimo climático; su asociación con amancaes, juncos y cola de caballo hace pensar en un abundante consumo de vegetales, pero cuando a este contexto se incorpora las estólicas con punta de obsidiana y las pieles de guanaco y vicuña que aparecen también en el yacimiento, entonces se observa que la tendencia económica primaria está en la caza aún. Engel insiste en sus interpretaciones arcaizantes cuando dice que el uso de las pieles de vicuña y guanaco debe considerarse como "índice de que ha nacido temprano el pastoreo" (1966a: 31).

Adicionalmente, es interesante observar que, en asociación con este contexto hay aglomeraciones de poco numerosas "chozas" circulares de 5 a $6 \mathrm{~m}$ de diámetro, que rodean una casa central de mayor diámetro $(11 \mathrm{~m})$ en las lomas o muy cerca de ellas. Las lomas eran apetitosos centros de abastecimiento de animales y plantas para recolectar. 
Engel indica que ha encontrado semejantes asociaciones también en Chilca y Lurín, hacia 5 mil años a.C., a diferencia de lo que Paracas que tiene una antigüedad de 6870 a.C ${ }^{3}$.

Por los morteros encontrados por Rex González (1960) en las cuevas de Intihuasi (Argentina) y los encontrados por Edward Lanning en Ancón, se puede suponer que al menos durante el Ayampitiniense -y aún antes- como ya está dicho, se consumían granos $\mathrm{u}$ otros productos vegetales harinosos.

\section{El Arcaico Inferior}

Este periodo está comprendido entre los años 4000-2500 a.C. ${ }^{4}$ Para él se mencionan 6 plantas "domesticadas", dos de ellas son leguminosas, una es un fruto (lagenaria), otras dos son el junco y la totora y la última es una tuberosa. A este complejo se le agrega esta "especie de yuca" que no tiene aún identificación y que bien pudiera ser un tallo de planta no cultivada.

Las plantas son:

Phaseolus lunatus (pallar)
Phaseolus vulgaris (frijol)

Scirpus Sp. (junco)

Cyperus Sp. (totora)

Pachyrrhizus Sp. (jícama) (especie de yuca?)

Lagenaria siceraria (,) (calabaza)

Es probable que los "Phaseolus" hayan sido propiamente cultivados, pese a que las evidencias formales de su ubicación no están bien determinadas; lo mismo se puede decir de la Lagenaria, que probablemente es la "calabaza" a la que se refiere Engel (1966: 63). En cambio, el junco, la totora y aún la jíquima (cuya presencia no está bien establecida), deben corresponder a plantas recolectoras; aún hoy, las dos primeras no son, propiamente, productos del cultivo. Si bien el uso de estas plantas, pone la alimentación, está probado, sin embargo, la mayor parte de su utilidad se centra en la confección de esteras, cuerdas, canastas, etc., dentro de una tradición que puede ser previa.

El pallar y el fríjol, con plantas muy comunes en Mesoamérica y muchos especialistas proponen México y Guatemala como probable foco cultígeno, aunque en los Andes Centrales existe una variedad silvestre

3 Aparte de que las evidencias de cultivo para los establecimientos de Paracas, Lurín y Chilca, a los que Engel atribuye una tal antigüedad, no son lo suficientemente convenientes, lo cierto es que tampoco lo son las fechas radiocarbónicas. El mismo Engel (1966a: 77 ss) da para Santo Domingo de Paracas las siguientes referencias:

Muestra I $-1311-8830 \pm 190=6870$ a.C.

Muestra GX $-218-5890 \pm 145=3930$ a.C.

Ambas muestras, tan diferentes en el tiempo, deben su diferencia a su tratamiento en laboratorios distintos, pero debido a que no se justifica tal distancia cronológica (3000 años) Engel arbitrariamente rechaza la fecha de 3930 a.C., como "posiblemente aberrante" y por eso no la utiliza en la discusión de sus materiales. En el caso de las muestras de Chilca sucede también algo parecido:

Muestra I $-1192-6970 \pm 300=$ a 5010 a.C.

Muestra I $-1387-5100 \pm 150=$ a 3140 a.C.

Ambas muestras son del mismo contexto estratigráfico y probablemente parte de una sola; sin embargo, dan dos fechas alejadas en casi 2000 años. Engel sólo usa la más antigua de sus discusiones.

La muestra de Lurín (GX - 264) procedente del sitio de La Centinela da $7270 \pm 125$ (5310 a.C.) pero es sola y no tiene otras para confirmar.

Parece útil tener precauciones, por ahora, en el uso de estas fuentes cronológicas.

4 La mayor parte de las fechas son procedentes del "Monumento I" de Chilca, de sus niveles inferiores (muestra NZ 1050), medianos y terminales (Engel, 1966a).

Muestra NZ - 1053 - $5700 \pm 136$ (3740 a.C.)

Muestra I $-892-5410 \pm 275$ (3450 a.C.)

Muestra UCLA - $664-5370 \pm 120$ (3410 a.C.)

Muestra I - $817-5250 \pm 220$ (3290 a.C.)

Muestra I - 815 - $5025 \pm 200$ (3065 a.C.)

Muestra I - $745-4975 \pm 160$ (3015 a.C.)

Muestra I - $814-4950 \pm 220$ (2990 a.C.)

Muestra I - $816-4500 \pm 190$ (2540 a.C.) 
de Phaseolus Sp., llamado "chui", que indica que debe tenerse en cuenta esta área también para el debate de origen de la domesticación de los Phaseolus (Towle, 1961: 100). Son plantas de origen subtropical, perfectamente coincidentes, ecológicamente, con los valles de la costa peruana y valles bajos interandinos: por el momento, como es casi todo, las referencias sólo son de la Costa.

Por las evidencias disponibles, el Arcaico Inferior es una etapa que se caracteriza por un modo de producción predominantemente recolector, con ensayos ya avanzados en la domesticación de algunas plantas, especialmente leguminosas, de probable origen local.

El contexto dentro del que se desarrolla tal régimen económico, es probablemente diferente al de los recolectores del Optimun Climáticum, aunque subsisten, entre los $\mathrm{Ar}$ caicos la mayor parte de los viejos patrones. A los "ayampitinenses" se les reconoce por su vivienda en cuevas y en estaciones nucleadas en terrenos abiertos; así las evidencias cronológicas de Engel tienen algún valor (ver nota 3 informe), entonces es posible pensar en que tales estaciones abiertas, son realmente una especie de "fondos de cabaña" ligadas a una situación de recolección avanzada y, en consecuencia, antecedentes de las estancias que caracterizan al Arcaico Temprano. Engel ha encontrado tales estancias en Río Grande de Nasca, en Chilca y en Paracas (Engel 1964; Donnan 1964), por chozas construidas a base de tallos de junco y, en algunos casos, de palos de totora para la armazón. Las casas son generalmente circulares aunque algunas cabañas de Río Grande afectaban formas rectangulares.

Por otro lado, las estancias estaban ya un tanto alejadas de las lomas y más bien cerca de las márgenes de los ríos, lo cual probablemente era consecuencia de los comienzos en el interés por las plantas cultivadas.
La pesca con anzuelo y arpón subsistía, a1 mismo tiempo que la caza del lobo marino y la recolecta de mariscos.

\section{El Arcaico Superior}

Este periodo tiene dos fases no bien diferenciadas: "precerámica" y "cerámica"; pero desde el punto de vista económico no tiene sentido tal diferencia. Al parecer tampoco tiene gran importancia en el comportamiento social en general. La aparición de la cerámica, al menos en la Costa, no pasa de ser, como las demás tecnologías, un paso más al proceso evolutivo de la sociedad andina, sin las implicancias revolucionarias que se le concedió casi siempre. En el sitio de Huaca Prieta en el valle de Chicama y en Guañape, en el valle de Virú (Bird 1948), así como en el templo de Haldas (Engel 1957) al parecer en Ancón (Ramiro Matos: comunicación personal), las evidencias señalan que la cerámica aparece por primera vez dentro de un contexto casi idéntico al del Arcaico inmediatamente anterior (agrícola incipiente). La cerámica adquiere un rol revolucionario mucho más adelante, junto con todas las demás tecnologías, luego de la "maduración" del Arcaico.

El Arcaico Superior es, probablemente, la época más importante en lo relativo a la "maduración" revolucionaria; en él se dan en la Costa y probablemente al mismo tiempo en la Sierra y en la Selva (o ceja de Selva) la gran "acumulación" de los nuevos elementos que habrán de permitir el salto hacia la final caracterización de la Barbarie. Puede decirse que en el Arcaico Superior se logra tomar, por parte de "los Bárbaros", el control de la sociedad, para introducir todos los cambios necesarios para solucionar la crisis de los periodos anteriores.

Las referencias cronológicas hacen oscilar los comienzos de esta etapa entre 2500 y 2000 
a.C. y su terminación entre 1500 y 1200 de modo que tiene una elevación promedio de un milenio ${ }^{5}$.

Hasta este periodo de tiempo se domestica un porcentaje de plantas del margen del 50\% (de las plantas con datación conocida incluidas las ya domesticadas en la fase anterior); adicionalmente se puede decir que ellas representan el 100\% de las plantas asignables a un "origen costeño" que fueron conocidas en el Perú y, en consecuencia, representa, este periodo, la total "saturación" de las posibilidades de domesticación de las plantas este territorio - la Costa.

Además de las plantas mencionadas para el periodo anterior, se agregan:

Canavalia Sp (legumbre)

Canavalia ensiformis (legumbre)

Gossypium barbadense (algodón)
Cucúrbita moschata (zapallo)

Cucurtiba ficifolia (zapallo)

Cucurtiba pepo (zapallo)

Capsicum Sp. (ají)

Bunchosia armeniaca (circuela del fraile)

Inga Feuillei (Pacae)

Psidium Guajava (lúcuma)

Canna edulis (Schira)

Typha angustifolia (totora)

Se señala como característica fundamental de este periodo, la presencia del algodón, que, en efecto, permite el crecimiento de una próspera industria de tejidos y redes.

Es evidente que, en este tiempo, la mayor parte de las plantas eran cultivadas, lo que es cierto, sobre todo, para las leguminosas (phaseolus y Canavalia), para el algodón, los zapallos (cucurbita) y las calabazas (lagenaria). Las fru-

5 Las fechas que registra Engel (1966a) para esta época (todas referidas a sitios sin cerámica) son las siguientes: I - 1091 (Moya VI - Chilca)

$4305 \pm 275$ (2345 a.C.)

I - 956 (Achupayes I - Chilca)

$4305 \pm 500(2345$ a.C. $)$

C - 313 (Huaca Prieta - Chicama)

$4257 \pm 250$ (2307 a. C.)

C - 362 (Huaca Prieta - Chicama)

$4044 \pm 300$ (2094 a.C.)

NZ - 370-4 (Otuma XII, Paracas)

$3950 \pm 80$ (1900 a.C.)

NZ - 308 (Río Seco del León - Costa Central)

$3800 \pm 100$ (1850 a.C.)

NZ - 370-2 (Las Aldas - Costa Norte)

$3800 \pm 80$ (1850 a.C.)

NZ - 285 (Río Seco - Costa Central)

$3740 \pm 100$ (1790 a.C.)

$\mathrm{NZ}$ - 370-3 (Otuma GM - Paracas)

$3600 \pm 140$ (1650 a.C.)

I - 1444 (Piedra Cgrande - Chilca)

$3600 \pm 140$ (1650 a.C.)

Gak - 107 (Las Aldas - Costa Norte)

$3580 \pm 130$ (1630 a.C.)

C - 315 (Huaca Prieta - Chicama)

$3572 \pm 220$ (1622 a.C.)

I - 1676 (Chuquitanta - Chillón)

$3570 \pm 150$ (1620 a.C.)

I - 1435 (San José VI - Chilca)

$3520 \pm 125$ (1570 a.C.)

GIF - 74 (Trapiche - Chillón)

$3275 \pm 240$ (1325 a.C.)

NZ - 319 (Asia I - Omas)

$3270 \pm 100$ (1320 a.C.)

I - 1290 (Mencos I, Chilca)

$3236 \pm 175$ (1286 a. C.) 
tas tales como el ají, la ciruela, el pacae, la guayaba o la lúcuma, eran, seguramente, aprovechadas sin cultivo, como sucede aún hoy, parcialmente, poniendo algún cuidado en su protección contra animales y plagas y, en todo caso, proveyéndolo de humedad por medio del acarreo de agua (?).

Engel (1966a) separa este periodo en tres fases, en función de la mayor o menor complejidad de los centros de población; parte de una fase comprendida entre 2550 y 1850 a.C. con "realizaciones sencillas"; una segunda fase comprendida entre 1850 y 1550 a.C.; con pueblos con arquitectura y centros comunales; y, una última fase comprendida entre 1550 y 1300 a.C., con pueblos con grandes complejos arquitecturales. Si bien el ajuste cronológico no tiene que ser absoluto, la secuencia postulada por Engel es un buen indicio del crecimiento de las aldeas de este tipo, paralelamente a la domesticación.

El crecimiento paulatino de la población es otra consecuencia del aumento de plantas domesticadas, lo cual determina que en valles aún tan pequeños como el de Chilca, Engel encontrara hasta 24 sitios de la época. La dieta alimenticia, sin embargo, no era aún "vegetariana" esencialmente, puesto que las plantas que hay no son lo suficientemente ricas como para responder al crecimiento demográfico de los aldeanos "arcaicos". En la Costa, los mariscos eran lo más importante, junto al lobo marino, pero lo que es evidente es que la tendencia ya se había perdido, tanto que los instrumentos de producción propios de esta etapa corresponden casi exclusivamente a fines de recolecta, pesca y probablemente agricultura.

Las leguminosas juegan un papel notable: de "centro" de la domesticación y, quizá; junto a ellas el algodón. La importancia de los pallares y el fríjol sólo se asemeja a la del maíz (Zae maya) cuya presencia en los Andes puede coincidir con la finalización del Arcaico o los comienzos del Formativo.
El Arcaico Inferior es, en base a esta evidencia, el inicio de la agricultura aldeana, el origen de la Barbarie, aunque debe considerarse como una etapa de lucha por una nueva dieta alimenticia, sin asentamiento o estabilidad de ninguna clase. Es experimental y transicional. Se supone la acumulación del mayor número de novedades "etnobotánicas" producido en época alguna, que se completará durante el Formativo Inferior. En el Arcaico Superior se estructura el cuadro agrícola, provocando un cambio irreversible de naturaleza cualitativa. Esta es propiamente la época de la Revolución Agropecuaria.

En el orden social, se cambia paulatinamente de la estancia o el campamento hacia la aldea autosuficiente; se crean las condiciones para un gran despliegue demográfico, asociado a la movilización y el intercambio de distintas regiones. La aparición de los centros comunales y probables centros ceremoniales incipientes, a la finalización del período, crea las condiciones favorables a la organización tribal y el surgimiento de regímenes teocráticos propios de la Barbarie.

En el orden de la producción tecnológica y del arte, así como en toda la estructura ideológica hay una serie de pequeños cambios sumamente interesantes en el proceso de sus correspondientes roles en la situación revolucionaria.

Aparece el tejido de algodón, hecho sin telar, por medio del anudado o entrelazado de los elementos, siguiendo los originales procedimientos de la cestería (aunque no copie sus técnicas) previamente desarrollada y del tejido de fibras de junco y ágabe del Arcaico Inferior. Aparece la cerámica, la arquitectura, la escultura, etc.

\section{El Formativo INFERIOR}

Es una época todavía oscura, pero sin duda representa la clave en el estudio de este proceso, 
pues en ella culmina la "acumulación" de cambios en todos los órdenes de actividad social. Es muy probable que en este periodo se dé un grado muy elevado de movilidad poblacional, permitiendo así el intercambio de productos y experiencias entre las regiones subtropicales, tropicales y cordilleranos que existen en el Perú.

Parece que la historia de la Barbarie en el mundo muestra un estadio en el que la búsqueda de tierras y recursos agrícolas permite grandes desplazamientos de los agricultores en zonas muy variadas. El proceso que Gordon Childe describe para el Cercano Oriente, en su expansión a Europa y el Asia Oriental revela una situación de esta naturaleza, que permite la emergencia de la nueva sociedad "Neolítica", estructuralmente diferente a la "Paleolítica".

Generalmente, esta etapa se reconoce por la presencia de "cerámica pre-Chavín" o "noChavín", asociada a un contexto semejante al de los más avanzados agricultores del Arcaico, es decir, con aldeas y centros ceremoniales. Naturalmente, sin embargo, es mucho más importante que eso, la asociación con un nuevo complejo alimenticio, en el que el maíz, la llama domesticada y la papa juegan un rol de primerísima importancia.

Pero, como está dicho, muy poco es lo que se ha estudiado sobre este tiempo, por lo tanto, las referencias no son tan precisas como las de la época anterior o las de más adelante.

Un criterio para ubicar los establecimientos es la cerámica anterior a Chavín o, en general, la que data de los siglos anteriores a la gran expansión de Chavín ( \pm 800 a.C.) Este criterio hace oscilar los inicios de la época entre 1800 y 1200 a.C., siendo su culminación entre 1000 y 800 a.C., lo que indica un periodo de más o menos medio milenio. ${ }^{6}$

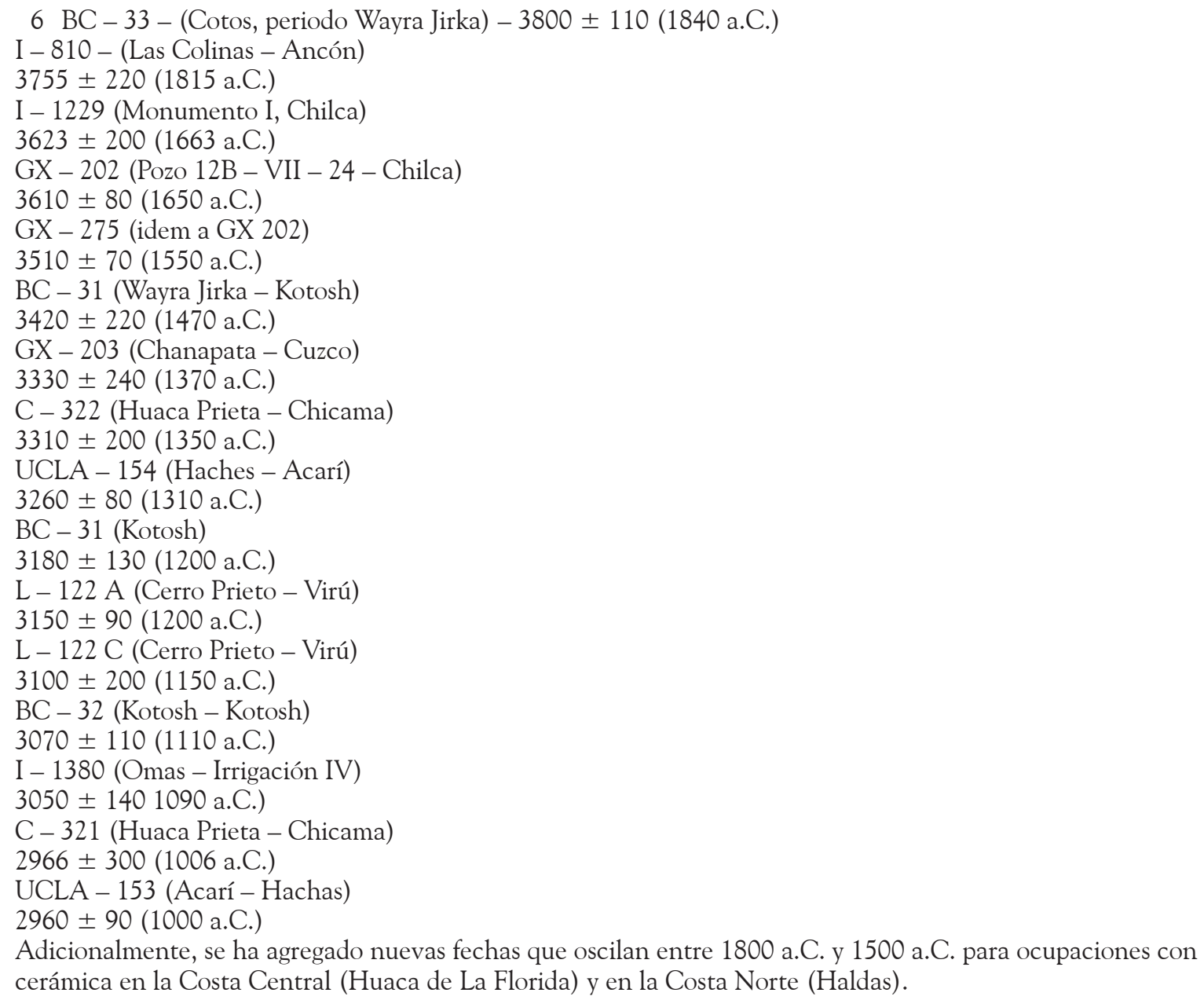


La importancia de esta época reside -en lo que a plantas se refiere- en la incorporación integrada de la agricultura andina con plantas de origen cordillerano y tropical, siendo posible que algunas de las últimas pudieran haber sido domesticadas originalmente en Mesoamérica.

Es la época en la que se asientan el maíz y la papa, una de origen subtropical o tropical y la otra característicamente cordillerana.

Es probable que así como en la Costa se dio un "Arcaico de leguminosas, cucurbitáceas y algodón”, en la Sierra se diera paralelamente un "Arcaico de gramíneas, tubérculos y animales domesticados", mientras que ya sea en la Selva alta oriental, o en cualquier área cercana o lejana (Amazonas, Colombia o Mesoamérica) se produjo también un "Arcaico" que permitió "exportar" el conjunto de plantas de carácter y origen tropical.

No está aún bien determinada la manera como pudieron integrarse el conjunto de plantas que conforman el complejo etnobotánico andino, lo cierto es que ello debió producirse en el Formativo Inferior, puesto que en el Superior esto ya está dado. Las posibilidades son muchas, el hecho hasta hoy evidente es que fue el producto de mucho intercambio regional e interregional, No parece ser que las plantas "tropicales" llegaran en grupo, en conjunto, como consecuencia de una migración o algo semejante, sino poco a poco; el maní, por ejemplo, parece haberse incorporado a fines del Arcaico y lo mismo se puede decir de el maíz. Del complejo cordillerano, la papa debe haber sido la más aceptada en el área en general, aunque su papel en la altiplanicie, junto con todo el "complejo cordillerano" habla de una situación muy avanzada de la Sierra andina hacia los comienzos del primer milenio de la era pasada.

El "complejo cordillerano" es el siguiente:

Chenopodium quinoa (Quinua)

Chenopodium pollidicaule (Cañihua)

Solanum tuberosum (papa o patata)
Oxalis tuberosa (oca)

Tropaeolum tuberosum (mashwa)

Ullucus tuberosus (olluco)

Por el momento sólo la papa y la quinua han podido ser fechadas gracias a los hallazgos de Chiripa (Bolivia) y el norte de Chile (Bird 1946). Las demás plantas no han sido aún encontradas en yacimientos arqueológicos, pero también son las menos importantes. La antigüedad conocida es del orden del año 1000 a.C., de la papa deshidratada (chuño) y de quinua (Ponce Sanjinés 1961). La quinua, además parece haber jugado un rol de importancia entre grupos de salvajes de Atacama y Arica que evidentemente la adquirían de algún modo del Altiplano; existen evidencias recuperadas por Junius Bird y Lautaro Núñez (comunicación personal) de verdaderos depósitos de granos de quinua, enterrados como ofrendas mortuorias.

Como señala Horkheimer (1958: 70), el contenido alimenticio de la quinua es tan alto que con sólo quinua se puede reemplazar una gran deficiencia de otros alimentos; Horkheimer da los siguientes valores:

Quinua: $10.7 \%$ de proteínas

$5.2 \%$ de grasas

$69.2 \%$ de hidratos de carbono

353 calorías (en 100 gr de quinua)

En comparación, el maíz solamente tiene:

$7.6 \%$ de proteínas

$3.7 \%$ de grasas

$73.4 \%$ de hidratos de carbono

343 calorías (en 100 gr de maíz)

mientras el trigo, de origen euroasiático, y de gran consumo en Occidente, tiene:

9.2\% de proteínas

$1.5 \%$ de grasas

$71.6 \%$ de hidratos de carbono

328 calorías (en 100 gr de maíz)

De todo esto se observa que la quinua es un grano cuyo contenido proteínico y de calorías, es mayor que los del maíz y el trigo, que, sin 
embargo, tienen mayor popularidad en América y el mundo, respectivamente.

El complejo "tropical - semitropical" es el siguiente:

Zea mays (maíz)

Manihot utilissima (yuca)

Ipomoea batatas (camote)

Acharis Hypogea (maní)

Persea americana (palta o avocado)

Solanum muricatum (pepino)

Cyclanthera pedata (caywa)

Annona muricata (guanábana)

Arracacia Xanthorrhiza (Arracacha)

Carl Sauer (1949) considera que de estos, el maní y la yuca son originarios de la Selva amazónica, lo cual es muy probable. El pepino y la caywa pueden tener su origen en la costa peruana y aún la última, en los valles interandinos. En lo que se refiere al maíz, aunque algunos especialistas persisten en la probabilidad de un centro andino de origen independiente del mesoamericano, las probabilidades de que su domesticación se haya realizado sólo en dicha área son mayores, dado que allí existen un Arcaico largísimo, que domesticó el maíz hacia 5000 a.C. o antes. Junto con el maíz debieron llegar a los Andes otros elementos culturales, que se integraron en la configuración de la Barbarie Media, entre ellos ciertas formas de culto ligadas al felino, de la que aquí, por cierto, no nos ocuparemos.

La agricultura de la Costa, durante el Arcaico, ha sido considerada "incipiente" y esto es cierto, puesto que no afectó sustancialmente la actividad social global, pese a los cambios de orden cuantitativo ya enunciados. La agricultura de la Selva vecina a los Andes se quedó en la condición de "incipiente", pues no se integró con los productos cordilleranos y costeños o, por razones probablemente ecológicas (Meggers 1954) no logró "madurar" lo suficiente como para saltar al nuevo estado. La agricultura serrana en cambio, debe ser observada más finamente. El carácter "Arcaico" de la región cordillerana es un supuesto por com- paración más bien que una etapa establecida. Por el momento, sólo existen algunas evidencias aisladas e incompletas, como son las de la fase "Mito" de "Kotosh" (Huánuco), de la que sabemos que tuvo un desarrollo notable antes de la cerámica. En Mito, determinado por la Universidad de Tokio (Izumi y Sono 1963) a base del estudio de un conjunto de recintos ceremoniales, llamados los primeros conocidos: "Templo de Manos Cruzadas" y "Templo de los Nichitos", se conoce la subsistencia de la tradición de caza con una industria muy parecida a la "ayampitinense", pero no se sabe si, en asociación a esto, habían ya formas agrícolas de algún tipo, porque no se han hallado las evidencias (Seiichi Izumi, comunicación personal). Es presumible que así sea, pero la presunción no es un método científico. En todo caso, el adelanto tecnológico es similar al del Arcaico Superior Costeño, con el que tiene muchas coincidencias, que aquí no discutimos por ser otro capítulo del problema.

En Lauricocha, que se diferencia de Kotosh tanto por la altitud (alrededor de $2000 \mathrm{~m}$ más alto de Kotosh) como por las condiciones ambientales consecuentes, la fase III parece coincidir con la fase Mito, lo que cuenta con evidencias de sincronía y de características homotaxiales. Pero, tampoco hay la evidencia vegetal recuperada; quizá nuevas excavaciones allí den más elementos de juicio, aunque tanto la altitud como el carácter de pradera de Lauricocha, seguramente permiten una insistente retención del carácter "salvaje", favorable a la caza, de los habitantes de las cuevas. Naturalmente no estamos en condiciones de decir que la agricultura probable de Kotosh tuvo que ser la "cordillerana".

El territorio clave para esto es, a nuestro entender, el altiplano del Titicaca, con probables extensiones hacia la Sierra sur y central del Perú y hacia las cordilleras orientales de Bolivia. No solamente por el hecho fortuito de haber encontrado en esa zona las hasta hoy más viejas evidencias de papa y quinua, sino, además, por las condiciones favorables del al- 
tiplano, tanto para el cultivo de estas plantas, como para el hecho aún más importante de la domesticación de animales. El "complejo cordillerano" es una asociación indestructible animal-vegetal, con el papel predominante de la papa, la quinua y la llama. Por otro lado, el régimen agrario "cordillerano" es cualitativamente distinto del "tropical" y "Subtropical", en tanto que mientras la agricultura de las tierras bajas supone, para su desarrollo, de la hidráulica, de las técnicas de la irrigación, la agricultura de las tierras altas; la de estas plantas, se desarrolla simplemente en función del régimen de secano, con muy pocas exigencias de humedad y con una gran resistencia a los contrastes de temperatura y las plagas. Por eso, es un error considerar que la sociedad andina, en general, fue de "carácter hidráulico" (Steward 1955; Wittfogel 1964), es un error de generalización que se basa exclusivamente en los conocimientos adquiridos en la arqueología de la Costa. Pero, al mismo tiempo, conviene recordar las características que Dollfus (1965: 228) le asigna al "Optimum Climatium" en la Sierra: estación húmeda contrastante con la estación seca y, en la estación seca, "vigorosos contrastes térmicos cotidianos". Esto, tanto la estación húmeda como la seca, son sumamente favorables al desarrollo del régimen cordillerano: agropecuario, con el tipo de plantas y animales propios del "complejo". Es posible pensar que ya en la cordillera se había producido una revolución agropecuaria cuando el Formativo se hizo manifiesto en la Costa y en la Sierra central y norte del Perú. Todo parece indicar que también la pesca de lago tuvo algún papel en el proceso.

La papa y la llama, son factores definitivos en la eclosión revolucionaria de los Andes, tanto o más que el maíz. No debe olvidarse que en México durante milenios el maíz, ya domesticado, no afectó revolucionariamente a la sociedad, como tampoco lo hizo en la Selva vecina de los Andes y en otros tantos territorios. En México mismo, la eclosión revolucionaria, como lo van demostrando los estudios de McNeish, sólo se produjo por la maduración de las condiciones, hacia fines del segundo milenio de la era pasada. Un estímulo innegable para la aceleración del proceso fue el paso del Post-Glacial Medio al Tardío, con sus consecuencias climáticas adversas como lo han señalado Childe, Cole (1965) y Braidwood (1950), para el Cercano Oriente y lo propone Lorenzo (1961) para Mesoamérica.

Todo esto nos demuestra que no es, pues, la agricultura (como técnica) en sí misma, y mucho menos el "carácter hidráulico" y de ella, la que supone un cambio fundamental en la sociedad "recolectora"; es solo uno -probablemente el más importante- de los factores determinantes del proceso. Lo es también la domesticación de animales y, por cierto, el crecimiento, el desarrollo de los instrumentos de producción y su consecuente utilización por el pueblo.

Las leguminosas, frutas, etc. cultivadas en la Costa durante los milenios cuarto, tercero y segundo de la era anterior, no provocan un cambio sustancial en la dieta alimenticia, la cual se basa aún en la recolecta y la caza (en lo que ésta es posible) como factores fundamentales de producción y consumo. El papel de los productos marinos es incalculable; es lo que mantuvo estable o aumentó el promedio de vida de la población. La producción agraria era suplementaria y es probable que dentro de un indicador porcentual no suponga más de un 20\% o 30\% creciente: al fin del Arcaico Superior, en uno más del 50\%, deducido por comparación con determinaciones semejantes, hechas por McNeish para México (1958). En cambio, en el Formativo, con el ingreso de los nuevos productos, la dieta se enriquece notablemente con plantas cultivadas, y, por cierto, especialmente con productos como el maíz, la papa, la yuca, la llama domesticada, etc.; que a partir de entonces se convierten, junto con el fríjol y el pallar, en los fundamentos mismos de la alimentación andina.

No se trata de que los productos fueron "autóctonos" o "alóctonos" lo importante es que 
ellos jugaron un papel de conductores de cambio social, sólo gracias a que las condiciones ambientales y tecnológicas previas, favorecieron su desarrollo explosivo en un momento dado.

\section{El Formativo Superior}

El Formativo Superior, para los Andes Centrales, está determinado por la expansión y el desarrollo de una cultura que los arqueólogos, a partir de Julio C. Tello, conocen con el nombre de Chavín. Para el Altiplano Sur, cuya importancia en el Formativo no ha sido suficientemente aquilatada, no existe la referencia en un "Formativo Superior"_independiente de las culturas Qaluyu y Chiripa a no ser este nivel los recientes hallazgos por Ponce Sanjinés (1961) en Tiwanaku y, probablemente, la cultura Pukara de la sección occidental-norte del Titicaca. En este trabajo, en espera de más datos para este período en el Sur, nos limitamos a discutir Chavín, cuya área cubre la Costa y la Sierra norte y la costa sur del Perú.

Solo como referencia, deseamos anotar que en la cerámica Pucara, cuyos inicios se remontan tan solo al siglo II antes de esta era, se observa (Lumbreras y Amat) la subsistencia de la caza de aves (patos) lacustres, a la vez que el conocimiento y seguro consumo de la perdiz (Gallinacea cordillerana) y el uso plenamente demostrado de los auquénidos como animales de carga, algunas figuras sugieren incluso la Alpaca (Lama pacus), que, según la opinión de algunos especialistas serían una especie aún más perfeccionada (por selección domestica) que la llama (Lama glama), ambas aparentemente originarias del guanaco (Lama guanicoe). En el Sur, Pucara es lo que más corresponde al criterio de "Formativo Superior" que está ligado a Chavín en el norte, pese a la diferencia cronológica y taxonómica.

El Formativo Superior, tal como lo conocemos hoy, se inicia entre los años 1000 y 800 a.C. y dura, irregularmente, hasta los siglos IV y I de nuestra era.
Este período se inicia con todas las ganancias del Formativo, es decir, que representa la total vigencia de la Barbarie, incluidos los ingredientes antitéticos cuyo desarrollo permitirá la destrucción de los bárbaros y el tránsito a la civilización. La aparición de una casta sacerdotal crecientemente poderosa, la especialización artesanal, el comercio interregional de manufacturas y productos agropecuarios, el crecimiento de los centros ceremoniales por encima de las aldeas campesinas, etc.; todo junto a una agricultura bien establecida y una ganadería creciente.

El Formativo Superior, en este trabajo, sirve más para demostrar la importancia de la fase anterior que para explicar su grandioso desarrollo. El, no es más que un índice del carácter de la fase previa, donde se inició el triunfo revolucionario. El hecho de que con Chavín encontramos una agricultura establecida, tendiente, en la Costa, a la terminología del regadío racionalizado; el uso de la lana y el algodón para la producción textil; el desarrollo de una arquitectura monumental exigente de una suerte de excedentes de productos del campo, el fortalecimiento de la alfarería artística y su alto índice de producción; la emergencia de la metalurgia del oro; el nivel artístico y técnico en el trabajo de la piedra con fines productivos y ceremoniales; la notable dimensión de los poblados y de los centros ceremoniales; las nuevas y revolucionarias formas del culto Chavín; etc. Todo esto no fue producto de una sorpresiva llegada de gentes de otros lugares, como ingenuamente creen -porque no lo pueden demostrar- algunos arqueólogos y publicistas; las evidencias señalan que todo es el producto de una revolución que se fue gestando desde milenos atrás, que concluyó con el Formativo Inferior y cuyos resultados se proyectan en la cultura Chavín, que por cierto tiene, en todos los órdenes de actividad social, los ingredientes cordilleranos, tropicales y subtropicales, que con tanta claridad denuncia el estudio de la evidencia etnobotánica. Chavín es la demostración de lo que pudo lograr la revolución agropecuaria en los Andes y, además, 
es, por ahora, la demostración más clara de que, en efecto, el proceso fue revolucionario.

No es, por cierto, pura casualidad el hecho de que el centro más importante de la cultura Chavín se halla establecido en el Callejón de Conchucos, en la Provincia de Huari (Ancash); Chavín de Huántar es un "punto de convergencia” de los complejos costeños, selvático y cordillerano; en Chavín, las recientes excavaciones (Lumbreras 1967) muestran productos de la Costa y de la Sierra y, al parecer, también de la Selva; lo último no es difícil dado que la Selva montañosa del Marañón se encuentra solamente a unos kilómetros de Chavín mismo, en la desembocadura del río Puchka.

Todo indica que al arribar al periodo Chavín, ya se había producido la "integración"; las evidencias no son muchas aún, pero, se sabe que en el Formativo Inferior, en la costa norte (Guañape Medio), en el sitio llamado el "Templo de las Llamas" en el valle de Virú, ya se usaba la llama (idomesticada?) en la liturgia (Strong y Evans 1952); parecido a lo encontrado en Chanapata, en el Cuzco (Rowe 1944). Es evidente, sin embargo, que la Costa mantuvo una agricultura más de acuerdo con su hábitat, favoreciendo esto la popularidad del maíz, las legumbres y las yucas. La papa pudo ser utilizada, en este tiempo, a través del trueque; fue la llama el vehículo más fácilmente "aceptado" en la Costa y en lugares como Cerrillos en Ica (Wallace 1962) la cantidad de restos de llama es considerable, no siendo este un animal de caza de este territorio, o, habiéndolo sido, no lo era tanto como para ser, según dice Wallace, el producto animal más popular. Por otro lado, la fase Isla de Wallace es básicamente la misma que la de Chupas en Ayacucho.

Finalmente, conviene recalcar que el total de piezas cuyas evidencias físicas han sido recuperadas por los arqueólogos, todos se encuentran desde el Formativo; las que se registrarían (25\%) como "posteriores", por haber sido encontradas en contextos más recientes, sino que se deben a indicaciones indirectas. Existen también muchas otras plantas cultivadas de las que sólo se conoce por mención de los cronistas o su presencia posterior. De acuerdo a Juana Infantes (1964) hubo un total de 88 plantas utilizadas para fines alimenticios, de los cuales 4 son cereales, 7 legumbres, 11 tuberosas, 40 frutales, 9 condimentos y 7 estimulantes. $\mathrm{Mu}$ chas de ellas probablemente sólo eran estimulantes. Margareth Towle (1961: 98) presenta 54 plantas utilizadas para la alimentación de las cuales sólo 36 tienen datación.

Las plantas hasta aquí referidas son:

Legumbres: Phaseolus lunatus (pallar)

Phaseolus vulgaris (fríjol)

Canavalia ensiformis (pallar)

Canavalis Sp. (pallar)

Pachyrrhizus Sp. (Jíquima)

Arachis hypogea (maní)

Cereales: Chenopodium quinoa (quinua)

Chenopodium pallidicaule (cañihua)

Zea mays (maíz)

Tubérculos: Ullucus tuberosus (olluco)

Oxalis tuberosa (oca)

Tropaelum tuberosum (mashwa)

Solanum tuberosum (papa)

Monihot utilissima (yuca)

Canna edulis (achira)

Arracacia xanthorrliza (arracacha)

Frutales :Capsicum Sp. (ají)

Bemchosia armeniaca (circuela del Fraile)

Inga fenillei (pacae)

Psidium guajava (guayaba)

Lucuma bifera (lúcuma)

Persea amaricana (palta)

Solanum miricatum (pepino)

Cucurbitáceas : Cucurbita moschata (zapallo)

Cucurbita pepo (zapallo)

Cucúrbita ficofolia (zapallo)

Lagenaria siceraria (calabaza)

Otros: Scirpus Sp. (junco)

Gossypium barbadense (algodón)

Typha angustifolia (totora)

Cyperus Sp. (totota).

Adicionalmente, hay otras plantas sin datación cronológica, que no hemos usado en la discusión, pero dada la menor importancia de 
ellas, frente a las mencionadas, no creemos que su "domesticación tardía" afectaría en nada lo aquí discutido. Debemos mencionar principalmente las siguientes, utilizadas en la alimentación (algunas de ellas, señaladas con asterisco, aparecen representadas en objetos artísticos de culturas recientes:

Polymnia sinchifolia (llacón)

Cyphomandra betacea (tomate)

Campomanesia lineatifolia (palillo)

Lupinus mutabilis (tarwi)

Amaranthus Sp. (bledos)

Xanthosoma Sp. (uncucha)

Annona cherimoglia (chirimoya)

Aristotelia macqui (maqui)

Carica caudicans (mitu, jerju)

Carica papaya (papaya)

Carycar aygdaliferum (almendra)

Passiflora Sp. (granadilla)

Del total de especies conocidas a la llegada de los españoles -datadas o no- el 54\% están reconocidas como "Formativos" o "Arcaicos" gracias a los datos de la arqueología y el restante $46 \%$ simplemente no tiene datación; mientras que el $100 \%$ de recuperadas in situ, tienen sus evidencias "originarias" a más tardar hacia el 800 a.C. (comienzos del Formativo Superior).

\section{La Tecnología Agraria}

Es demasiado poco lo que sabemos del desarrollo de las técnicas utilizadas en la agricultura y pese a que es un rubro diferente a la directa evidencia "etnobotánica" creemos que su permanencia es muy grande en la explicación del proceso.

Engel 1957, Bird y los demás arqueólogos que han escavado yacimientos arcaicos, declaran que no han encontrado los instrumentos que pudieron haber servido para fines agrícolas; unos palos aguzados al fuego pudieron cumplir la función de incipientes "azadones", quizá para sembrar las leguminosas; nada indica, durante ese tiempo, que se desarrollara una política hidráulica determinada; bien pudieron haber ciertas normas de irrigación como el simple aprovechamiento de la humedad proporcionada por las napas freáticas o la utilización relativamente racionalizada de las inundaciones ribereñas.

Durante el Formativo evidentemente se desarrolla un régimen de irrigación en cada valle costeño (Kosok 1965) lo que debe estar ligado a la complejización del agro con la introducción maíz. Nada hay, sin embargo, que se parezca a un azadón o a una hoz. Mucho más adelante, probablemente con el afianzamiento de la agricultura de la quinua, aparecen verdaderas hachas de piedra, así como azadores y otros instrumentos a manera de mazos para romper terrones; lamentablemente no sabemos cuando se iniciaron, y más bien parecen estar ligados a la Barbarie Superior y la Civilización.

\section{IMPORTANCIA DE LA EVIDENCIA VEGETAL}

La evidencia del cultivo y utilización de las plantas para el estudio del problema del paso a la Barbarie es de fundamental importancia, dado que es el ingrediente alimenticio que enriquece la dieta dando un cierto margen de seguridad en su obtención, además de permitir el establecimiento sedentario de una población numerosa. La agricultura y la ganadería son la base productiva que dio origen a la civilización humana; su gran desarrollo durante la Barbarie, capacitó al hombre para dominar la naturaleza en forma progresiva.

Lo que muestran las evidencias es que alrededor del año 4000 se inicia el cultivo de leguminosas y cucurbitáceas, con efectos cuantitativos y cualitativos casi imperceptibles; alrededor del año 2500 se inicia una nueva etapa con la domesticación de un mayor número de plantas y la utilización de muchos frutales, raíces, tubérculos, etc., manteniéndose la importancia de las legumbres y acumulándose el algodón como producto -sobre todo industrial- de primera importancia. Durante esta segunda fase del "Arcaico" existe un notable cambio cuantitati- 
vo, que se manifiesta en el aumento explosivo de nuevas plantas, especialmente tropicales y cordilleranas, que logran una modificación total en el régimen alimenticio de los pobladores andinos; la presencia de cereales; el incremento de legumbres y la complementación de los tubérculos ricos en harina, eleva el consumo de vegetales a un nivel muy alto de nutrición, dado que es posible controlar la producción de alimentos como el maíz y la papa, de alto contenido proteínico, de hidratos de carbono y calorías. La naturaleza de las plantas cultivadas desde entonces, tanto por su cantidad como por su calidad, hacen de esta última fase de domesticación, una etapa de cambio cualitativo de naturaleza irreversible.

Cabe destacar, además, que gracias a la evidencia vegetal es posible determinar la poligénesis de los productos que dieron origen a la agricultura y la sociedad andinas, poligénesis de la cultura que favoreció el asentamiento de la Revolución Agropecuaria y, en consecuencia de la Barbarie Andina. Este es el resultado de varias "evoluciones", dos de ellas evidentemente andinas (en la Costa y la Cordillera) y una probablemente extranjera; corrientes que coinciden en un proceso revolucionario cuyas fuentes se encuentran en la cordillera y en la Costa; no estamos aún en condiciones de decidir si la revolución agropecuaria en el Altiplano Sur, fue no independiente de la de los Andes Centrales, y, entonces, seguramente anterior y, en cierto modo, antecedente.

\section{Bibliografía Citada}

BIRD, Junius

1946 "The Cultural sequence of the North Chilean Coast". Handbook of South American Indians, vol. 2, pp. 587-594, Washington.

1948 "Preceramic Cultures in Chicama and Viru". Memoirs of the Society for American Archeology. № 4; pp.21-28.

BAIDWOOD, Robert J. and Linda

1950 "Jarmo: A village of Early Farmers in Iraq". Antiquity, vol. 24, pp. 189-195.
CARDICH, Augusto

1964 Lauricocha, fundamentos para una prehistoria de los Andes Centrales. Centro Argentino de Estudios Prehistóricos. Studio Prehistórico, III. Buenos Aires.

COLE, Sonia

1965 The Neolithic Revolution. British Museum (Natural History). Third Edition (reprinted).

COOK, O. F.

1937 "El Perú como centro de domesticación de plantas y animales". Servicio de Traducciones del Museo Nacional, № 1, Lima.

CHILDE, Vere Gordon

1959 Los orígenes de la Civilización. Breviarios del Fondo de Cultura Económica. México.

1960 Qué sucedió en la Historia. Ediciones Leviatán, Buenos Aires.

CHOY, Emilio

1960 "La Revolución Neolítica en los orígenes de la Civilización Americana". En Antiguo Perú: Espacio y tiempo, Librería Editorial Juan Mejía Baca, pp. 149-197. Lima.

DOLLFUS, Olivier

1965 "Effects des fluctuations et des accidents climatiques sur l'ecologie humaine du Pérou". Journal de la Société des Americanistes de Paris T. XLVI, pp. 67-155.

DONNAN, Christopher

1964 "An early house from Chilca, Peru". American Antiquitiy, vol. 30, № 2, part 1, pp. 13744. Menosha.

ENGEL, Frederic

1957 "Sites et établissements sons céramique de la Côte peruvienne". Journal de la Société des Americanistes de Paris, t. XLVI, pp. 67-155.

1964 "El Precerámico sin algodón en la Costa del Perú". Actas y Memorias del Congreso Internacional de Americanistas. Vol.3, pp. 141-52. México.

1966 Paracas, Cien siglos de Cultura Peruana. Librería Editorial Juan Mejía Baca.

1966a Geografía Humana Prehistórica y Agricultura Precolombina de la Quebrada de Chilca. Departamento de Impresiones de la Universidad Agraria, La Molina, Lima.

GONZALES, Alberto Rex

1960 "La Estratigrafía de la gruta de Intihuasi. (Prov. de San Luis, R.A.) y sus relaciones con otros sitios precerámicos de Sudamérica". Revista del Instituto de Antropología, Universidad Nacional de Córdoba, Tomo I pp. 5-302, Córdoba, Argentina.

HORKHEIMER, Hans

1958 La alimentación en el Perú Prehispánico y su 
interdependencia con la agricultura (mimeografiado). Programa de estudios de la zona árida peruana, UNESCO. Lima.

INFANTES VERA, Juana

1964 "Vegetales que los antiguos peruanos usaron para comidas y bebidas y que se usan actualmente". Actas y Memorias del XXXV Congreso Internacional de Americanistas, Vol. 3, pp. 153-68. México.

IZUMI, Seiichi; Sono TOSHIHIKO

1963 Andes 2: Excavations at Kotosh, Peru. Kodokawa Publishing Co., Tokyo.

KOSOK, Paúl

1965 Water, hand and Life in Ancient Peru. Long Island University Press. New York.

LORENZO, José Luis

1961 La Revolución Neolítica en Mesoamérica. Instituto Nacional de Antropología e Historia. Publicaciones 11, México.

LUMBRERAS, Luis Guillermo

1967 "Para una Revolución de Chavín”. Amaru, Revista de Artes y Ciencias de la Universidad Nacional de Ingeniería, № 2, pp. 49-60.

LUMBRERAS, Luis Guillermo; Hernán AMAT

Ms. "Secuencia Arqueológica del Altiplano Occidental del Titicaca". A publicarse en Actas del XXXVII Congreso de Americanistas, Argentina, 1966.

McNEISH, Richard

1958 "Preliminary Archeological Investigations in the Sierra of Tamaulipas". Transactions of the American Philosophical Society, Vol. 48, part 6.

MEGGERS, Betty

1954 "Enviromental limitations on the development of Culture". American Anthropology. Vol. 56, pp. 801-824.

PONCE SANJINÉS, Carlos

1961 "Fechas Radiocarbónicas de Bolivia". Diario Ultima Hora de 24-27 y 30-31 de octubre. La Paz. 1961a "Informe de Labores. Centro de Investigaciones Arqueológicas en Tiwanaku", Publicación № 1 . La Paz.

ROWE, John H.

1944 "An Introduction to the Archeology of Cuzco". Papers of the Peabody Museum of American Archeology and Ethnology Harvard University, vol. XXVII, № 2, Cambridge.

SAUER, Carl

1950 "Cultivated plants of South and Central America". Handbook of South American Indians, Vol. 6; pp. 487-543, Washington.

STEWARD, Julian (Editor)

1955 Las antiguas civilizaciones del viejo y el nuevo mundo. Serie monográfica. Unión Panamericana. Washington.

STRONG, William D.; Clifford EVANS

1952 "Cultural Stratigraphy in the Viru Valley, Northern Peru: The Formative and Florescent Epoch". Columbia Studies in Archaeology and Ethnology, Vol. IV. New York.

TOWLE, Margareth

1961 "The Ethnobotany of Precolumbian Peru". Viking Fund Publications in Anthropology, № 30, Chicago.

TROLL, Carl

1958 Las Culturas Superiores Andinas y el medio geográfico. Trad. de Carlos Nicholson. Publicaciones de Instituto de Geografía de la Universidad de San Marcos. Lima.

WALLACE, Dwigth T.

1962 "Cerrillos, an Early Paracas Site in Ica, Peru”. American Antiquity, Vol 27, № 3, pp. 303-14. Menosha.

WITTFOGEL, Karl

1964 Depotismo Oriental, Ediciones Guadarroma. Madrid. 